\title{
Analisis Deskriptif Service Marketing Mix Bengkel Roda Dua Suzuki Magetan
}

\author{
Veny Ari Sejati ${ }^{1}$, Nunik Hariyani ${ }^{2}$

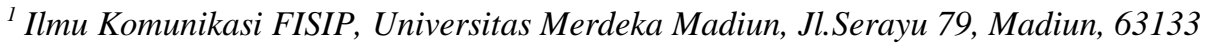 \\ E-mail: veny_ar@unmer-madiun.ac.id \\ 2 Ilmu Komunikasi FISIP, Universitas Merdeka Madiun, Jl.Serayu 79, Madiun, 63133 \\ E-mail: hariyani_nunik@yahoo.com
}

\begin{abstract}
In general, small-beginner workshops only apply traditional marketing and run as simple as possible. Problems arise as a result of the management of the marketing management of the workshop owner who is unable to answer the demands of the customer, causing loss of customers. The formulation of the problem in this study is how the integrated marketing services of the Suzuki Magetan workshop? this research is expected to be able to develop knowledge in the field of marketing communications, especially integrated marketing services, as well as providing knowledge to business startups to be used as a reference and help increase the number of customers. Customer is an asset that determines the company's growth and development. This type of research is qualitative descriptive, because it examines the integrated service marketing of a service company and uses qualitative descriptive research methods. Data collection techniques are complete participatory observation, unstructured interviews and documentation to obtain supplementary data. The purpose of this research are to improve the ability of researchers in the field of marketing communication, to be a means for researchers to publish the results of research in national scientific journals, initiating research road maps for researchers.
\end{abstract}

Keywords —: product; price; place; cyberspace; phisical evidence.

\section{LATAR BELAKANG}

Pada umumnya usaha jasa bengkel sepeda motor kecil-pemula menerapkan pemasaran tradisional dan dijalankan dengan pengetahuan seadanya. Hal itu sering menyebabkan bengkel tidak bisa bertahan lama, sehingga pemilik kerapkali beralih pekerjaan menjadi karyawan perusahaan lain, padahal sangat disayangkan, seharusnya mereka dapat membuka lapangan pekerjaan dan turut membnatu mengembangkan sector jasa di masing-masing wilayah apabila mereka dapat mempertahankan bengkel tersebut.

Salah satu tolak ukur kemajuan masyarakat suatu negara adalah diukur dari sector jasa. Menurut Lovelock (2002), sector jasa secara keseluruhan menjadi sector yang berperan penting dalam perekonomian dan dianggap sebagai tahapan tertinggi dalam proses perkembangan ekonomi. Di Indonesia saat ini sector jasa masih masih berkisar 40,4 persen terhadap GDP dibandingkan negara maju lainnya. Negara maju sektor jasa menjadi semakin dominan dengan semakin tingginya tingkat perekonomian (Widjaja, 2009)

Jasa (Lovelock, Patterson, Wirtz, 2015) adalah :

a. A service is any act, performance or experience that one party can offer to another and that is essentially intangible and does not result in the ownership of anything, but nonetheless creates value for the recipient. Its production may or may not be tied to a physical product.

b. Services are processes (economic activities) that provide time, place, form, problem solving or experiential value to the receiver.

Komponen utama jasa menurut Rust et al. (1996) (Widjaja, 2009) adalah service delivery yang merujuk pada kejadian yang benar-benar dialami oleh konsumen saat membeli jasa; service product merupakan hasil nyata dan perwujudan dari working plan; service environment merupakan physical backdrop yang ada disekitar penyampaian jasa, seingkali juga menunjukkan kelas segmentasi dan tanda untuk positioning perusahaan; dan physical product.

Karakteristik jasa adalah intangibility (tidak berwujud dan hanya dapat dirasakan oleh konsumen), inseparability (tidak terpisahkannya antara provider dan konsumen, keterlibatan konsumen dalam proses delivery jasa dalam proses produksi), variability (jasa sangat sulit dikontrol dan bersifat relative baik dari output provider maupun persepsi penerimaan konsumen), dan perishability (proses dan penggunaan dilakukan dalam waktu bersamaan sehingga tidak memungkinkan dilakukan penyimpanan) (Czinkota, M.R., Ronkainen, M.H. Moffet., \& E.O. Moynihan, 2001). Selain itu, karakteristik jasa juga bersifat lack of ownership(Tjiptono. Fandy; \& G. Chandra, 2005). 
Jasa adalah system yang digambarkan sebagai berikut:

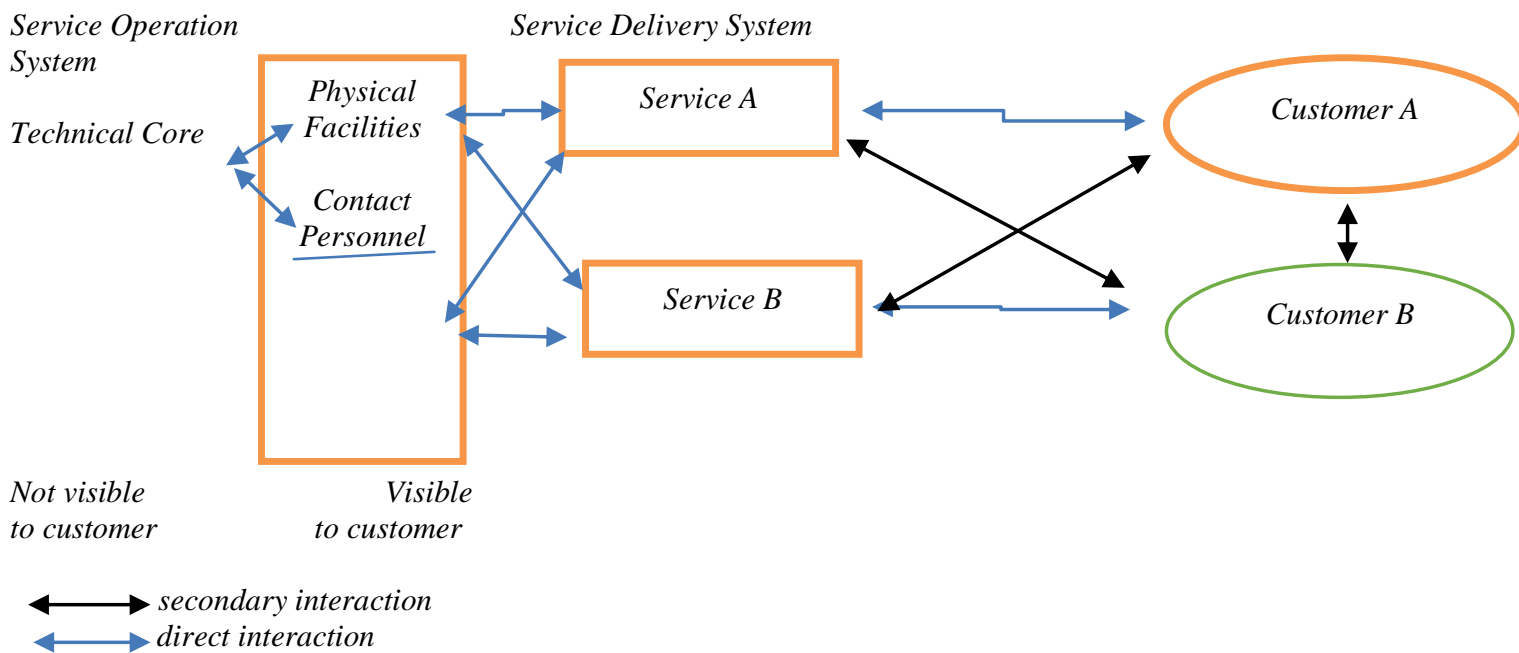

Gambar 1.The service business as a system(Lovelock, Patterson, Wirtz, 2015)

Permasalahan timbul akibat pengelolaan manajemen pemasaran bengkel kurang mampu menjawab tuntutan pelanggan sehingga menimbulkan hilangnya pelanggan. Pemasaran merupakan salah satu dari kegiatan-kegiatan pokok yang dilakukan perusahaan untuk mempertahankan kelangsungan hidupnya, untuk berkembang, dan mendapatkan laba (Dharmmesta.Basu S \& Hani Handoko, 2016). Tuntutan pelanggan pada pembelian produk jasa berdasarkan observasi peneliti secara langsung adalah biaya yang dikeluarkan seimbang dengan pelayanan atau manfaar yang didapat atau bahkan mendapatkan lebih. Pelanggan menginginkan pelayanan tulus luar dan dalam dari marketeers, bukan lips services(Kasali, 2010). Disini pengelola bengkel merupakan marketeer karena memasarkan jasa bengkel.

Ilmu pengetahuan formal dari sekolah berupa keahlian mesin merupakan salah satu kekuatan sekaligus peluang yang dimiliki oleh usaha jasa bengkel otomotive tingkat pemula skala kecil-menengah. Pada umumnya mereka adalah lulusan SMK teknik mesin yang memiliki kemauan kuat untuk membuka usaha bengkel otomotive. Selain itu, kekuatan dan peluang lainnya adalah mereka sudah pernah mengikuti kerja praktek minimal tiga bulan pada bengkel otomotive serta sudah pernah bekerja di bengkel jaringan resmi otomotive seperti Honda, Yamaha, Suzuki, sehingga sudah terbiasa berkomunikasi dengan pelanggan.

Dalam mengelola usaha bengkel milik sendiri harus memiliki pengetahuan pemasaran jasa dan diterapkan dengan konsisten, hal itu merupakan salah satu kelemahan yaitu jarang dimiliki usaha bengkel otomotive kecil-pemula. Mereka sering mengabaikan pentingnya pemasaran jasa. Hal itu dibuktikan dengan bentuk fisik bangunan dan penampilan lainnya yang kurang memadai, produk jasa maupun harga tidak terfokus, hanya mengandalkan words of mouth dalam lingkup lingkungan lokasi bengkel, dll.

Setiap bengkel jaringan resmi menerapkan pemasaran jasa terpadu (sevice marketing mix). Suzuki Magetan sebagai obyek penelitian ini adalah salah satu jaringan resmi pemasaran Suzuki roda dua di Jawa Timur, berlokasi di kota Magetan. Obyek memasarkan jasa perbaikan dan perawatan Suzuki roda dua atau bengkel resmi, selain memasarkan produk barang berupa Suzuki roda dua dan original spare-part. Pemilihan obyek didasarkan pada bahwa obyek penelitian merupakan small business yang menerapkan pemasaran jasa terpadu yang juga diterapkan di dua outletnya. Akan tetapi terdapat perbedaan program pemasaran yang diterapkan pada outlet yang berbeda wilayah, karena sosial, ekonomi, dan budaya masyarakat berbeda-beda.

Komponen service marketing mix meliputi produk (product), harga (price), lokasi (place), promosi (promotion), pengetahuan (people knowledge), proses (process), bukti fisik (physical evidence) (Widjaja, 2009). Bengkel resmi memiliki pemasaran jasa terpadu yang jelas dan dijalankan karena ada target yang harus dipenuhi pada setiap bulannya sebagaimana tertuang pada tujuan pemasaran, yaitu penambahan jumlah pelanggan baru serta income yang signifikan. Income yang maksimal dapat tercapai jika perusahaan memaksimalkan kepuasan pelanggan.Hasil penelitian ini diharapkan dapat bermanfaat bagi usaha bengkel pemula skala kecil dan dapat digunakan sebagai referensi dalam mengelola usaha bengkelnya.

\section{METODE PENELITIAN}

Jenis penelitian ini menggunakan kualitatif deskriptif, karena meneliti tentang pemasaran jasa terpadu suatu perusahaan jasa. Penelitian kualitatif menurut Bogdan dan Taylor (1992) adalah salah satu prosedur penelitian yang menghasilkan data deskriptif berupa ucapan atau tulisan dan perilaku orang-orang yang diamati. pendekatan kualitatif diharapkan dapat menghasilkan uraian yang mendalam tentang ucapan, tulisan, dan atau perilaku yang dapat diamati dari suatu individu, kelompok, masyarakat, atau organisasi tertentu dalam suatu keadaan konteks tertentu yang dikaji dari sudut pandang yang utuh, komprehensif, dan holistic (Sujarweni, 2014). Menurut Sugiyono (2013) "The characteristics of qualitative research are: qualitative research has the natural setting as the direct source of data and researcher is the key instrument, the data collected were in the form of words of picture rather than number, concerned with process rather than simply with outcomes or product, tend to analyses their data 
Website : http://sosial.unmermadiun.ac.id/index.php/sosial

inductively, "meaning" is of essentials to qualitative approach(Sejati, Handling of Costumer Complaint on the Small Business Services Field, 2017).

Penelitian deskriptif dilakukan untuk mengetahui nilai masing-masing variable, baik satu variable atau lebih sifatnya independen tanpa membuat hubungan maupun perbandingan dengan variable yang lain (Sujarweni, 2014). Penelitian deskriptif menurut Iqbal Hasan adalah penelitian yang dilakukan untuk mengetahui nilai variabel mandiri, baik variabel tunggal atau lebih (independen) tanpa membuat perbandingan atau menghubungkan dengan variabel lain (Murti,Endang, Retno I, Agus W, 2017).

Metode penelitian ini adalah naturalistic atau kualitatif, yaitu penelitian yang digunakan untuk meneliti pada suatu obyek yang alami dengan cara memberi pemaparan terhadap obyek tersebut. Peneliti sebagi instrument kunci yang akan membuat pemaparan dan penyimpulan (Sujarweni, 2014).

Peneliti tanpa mengetahui teknik pengumpulan data maka tidak akan mendapatkan data yang memenuhi standard yang telah ditetapkan(Sugiyono, Metode Penelitian Kuantitatif Kualitatif dan RD, 2013). Teknik pengumpulan data penelitian ini digambarkan berikut ini :

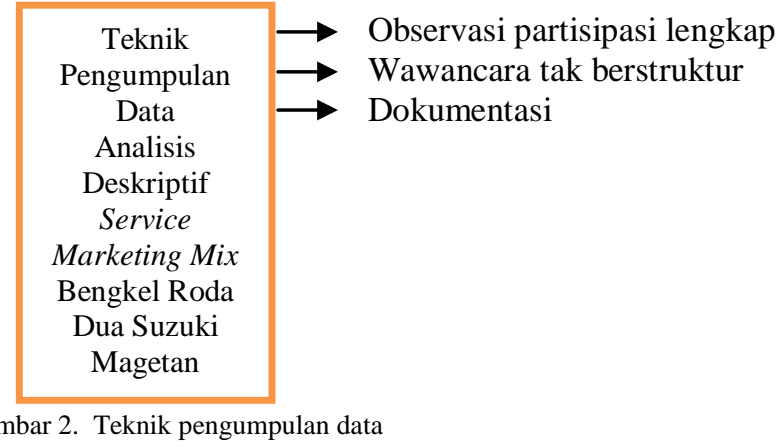

Dalam observasi partisipatif lengkap, peneliti terlibat sepenuhnya terhadap apa yang dilakukan sumber data, suasananya natural, dan tidak terlihat melakukan penelitian. Observasi tersebut dilakukan di bengkel Suzuki Magetan dan usaha bengkel kecil-pemula di Magetan. Wawancara tak terstruktur digunakan peneliti untuk mengetahui hal-hal terkait obyek secara mendalam, merupakan wawancara bebas dimana peneliti tidak menggunakan pedoman wawancara yang telah tersusun secara sistematis dan lengkap untuk pengumpulan data. Sedangkan data yang diperoleh dari dokumen berupa laporan penjualan harian dan bulanan, program pemasaran, kebijakan-kebijakan. Informan dalam wawancara tersebut adalah pengelola bengkel Suzuki Magetan dan konsumen, serta pemilik/pengelola bengkel kecil-pemula. Data tersebut digunakan sebagai pelengkap observasi dan wawancara agar hasil penelitian lebih kredibel.

Teknik analisis data menggunakan interactive model Miles and Huberman dalam Sutopo (1992), meliputi reduksi data, sajian data, dan penarikan simpulan atau verifikasi, aktivitasnya dapat dilakukan dalam bentuk interaktif dengan proses pengumpulan data sebagai proses interaktif (Sejati, Strategi Periklanan Pada Bisnis Retail, 2015). Model interactive digambarkan sebagai berikut (Sugiyono, Metode Penelitian Kuantitatif Kualitatif dan RD, 2013).

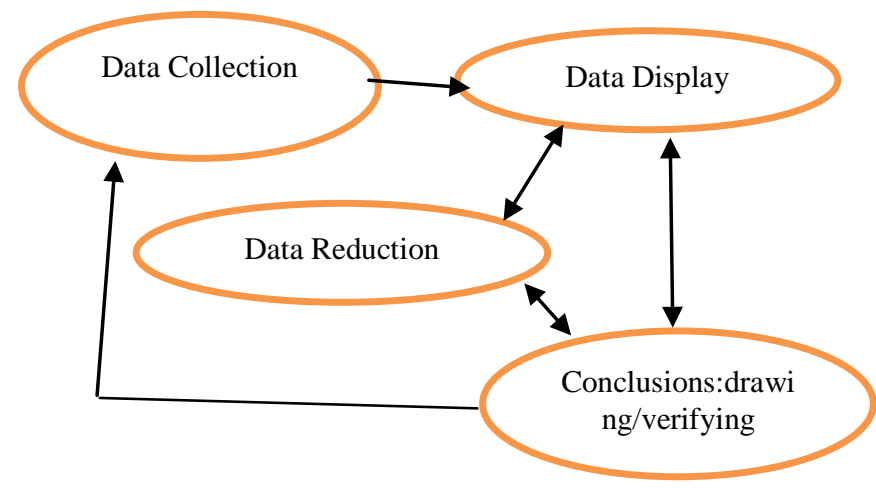

Gambar 3. Komponen dalam analisis data (interactive model)

\section{III.HASIL DAN PEMBAHASAN}

\section{A. Deskripsi Obyek Penelitian}

Obyek dalam penelitian ini adalah usaha bengkel Suzuki Magetan, merupakan salah satu jaringan resmi brand Suzuki Motorcycle berlokasi di MT. Haryono, Magetan, Jawa Timur. Obyek memiliki empat toolkit set serta peralatan sesuai dengan perkembangan teknologi sepeda motor, seperti mesin SOHC, DOHC, Injeksi (FI), dll, memiliki empat mekanik dalam melayani 
pelanggan, baik melayani onsite maupun panggilan secara kolektif. Obyek melakukan evaluasi program pemasaran bengkel setiap satu semester (enam bulan).

\section{B. Service Marketing Mix}

Adanya sifat-sifat khusus jasa seperti bergantung pada selera, kualitas jasa, perkembangan industry jasa, jasa tidak dapat disimpan, saluran distribusi tidak berperan penting, menyebabkan perlunya perlakuan khusus pemasaran jasa yang dilakukan melalui service marketing mix.

Service marketing mix terdiri dari 7Ps, yaitu produk (product), harga (price), lokasi (place) distribusi , promosi (promotion), yaitu people, process, dan physical evidence(Widjaja, 2009). Menurut Moriarty, dkk (2011), in the product there are design and development, branding, packaging, and maintenance(Sejati, Marketing Communication,Direct Marketing,Public Relation and Advertising, 2018). Produk jasa merupakan produk intangible yang dapat memberikan manfaat, memenuhi kebutuhan konsumen, dan dapat memuaskan konsumen. Strategi harga meliputi: premium, ekonomis, penetrasi, skimming. Sedangkan kategori strategi harga dapat dibagi sebagai berikut: defferential pricing strategies dan competitive pricing.

Penerapan pricing dapat dilakukan dengan mempertimbangkan aspek tingkat fungsional-psikologis jasa yang ditawarkan, persaingan, derajat keunikan jasa yang ditawarkan, target market, kombinasi product service dan cost based. Promosi berdasarkan definisi Morrissan (2010) adalah the coordination of all seller's efforts to setup channels of information(Sejati, Marketing Communication,Direct Marketing,Public Relation and Advertising, 2018). Dalam pemasaran jasa, komponen promotion mix menurut Kotler (2003) yaitu: iklan (advertising), promosi penjualan (sales promotion), direct selling (penjualan langsung), penjualan secara tatap muka (personal selling), hubungan masyarakat (public relation) (Widjaja, 2009). People merupakan asset utama pada industry jasa. Ketergantungan konsumen terhadap karyawan yang memiliki kinerja tinggi dan favoritisme merupakan penyebab konsumen puas dan loyal pada industri jasa. Pengetahuan digunakan untuk berinovasi dan digunakan untuk membangun atau memproduksi produk. Selain knowledge, attitude dan motivasi merupakan hal penting yang harus dimiliki karyawan. Apabila karyawan berkinerja tinggi berpindah perusahaan, maka konsumen kemungkinan akan berpindah mengikuti karyawan tersebut. Dalam Myelin, mobilisasi intangibles menjadi kekuatan perubahan, mengambil contoh TATA steel, tujuan strategi pengetahuan adalah meningkatkan kolaborasi dan percakapan antarkaryawan, mengurangi kehilangan modal pengetahuan saat karyawan meninggalkan perusahaan, mengurangi biaya, meningkatkan skala ekonomi, mempromosikan inovasi, serta meningkatkan produktivitas dengan cara menyediakan pengetahuan yang lebih cepat dan mudah dan mengurangi dampak sosial dari produksi (Kasali, 2010). Mutu layanan jasa bergantung pada proses penyampaian jasa kepada konsumen, provider jasa adalah karyawan sendiri maka untuk menjamin mutu layanan seluruh perusahaan harus dijalankan sesuai sitem dan prosedur yang terstandardisasi oleh kompetensi, komitmen, dan loyal pada perusahaan (Widjaja, 2009). Bukti fisik misalnya bangunan disertai interior, perlengkapan bangunan, dapat mempengaruhi mood konsumen. Bangunan harus dapat menciptakan atmosphere supaya dapat memberikan nilai tambah dan pengalaman konsumen. Penelitian sebelumnya menyatakan bahwa salah satu pendukung pemasaran lainnya adalah daya tarik design tata ruang showroom (Sejati, Peranan Sales Force Terhadap Repurchase Suzuki R2 Area Magetan, 2017).

\section{Produk (Product)}

Pada produk jasa, konsumen membeli manfaat dan merasakan produk. Product mix bengkel Suzuki Magetan digambarkan sebagai berikut:

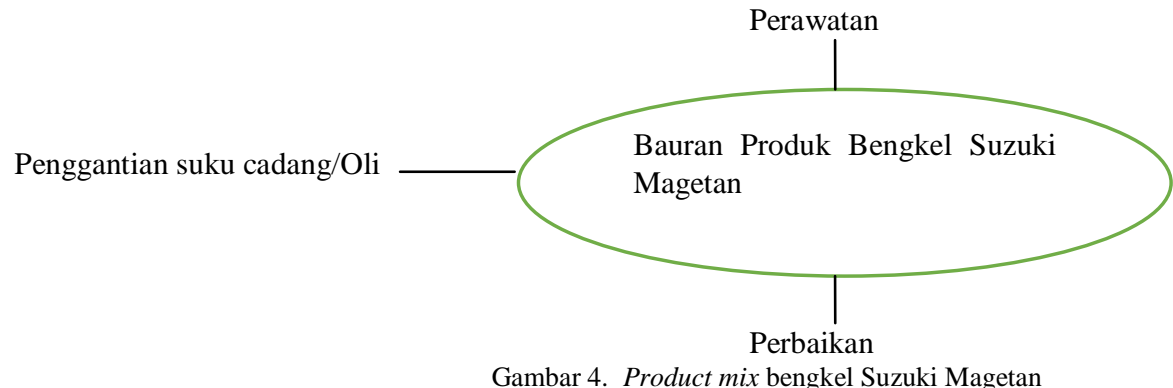

Perbaikan adalah pekerjaan memperbaiki kerusakan pada sepeda motor agar kembali normal, dan pekerjaan tersebut kerapkali diikuti penggantian suku cadang. Sebanyak 80\% kerusakan pada sepeda motor diakibatkan oleh suku cadang aus karena pemakaian dan menggunakan suku cadang tidak asli, sisanya diakibatkan oleh human error. Perawatan sepeda motor dilakukan pelanggan minimal satu bulan sekali atau sesuai kilometer yang disarankan oleh mekanik. Perawatan dilakukan untuk menghindari kerusakan lebih parah. Service counter merupakan sumber yang menginformasikan waktu perawatan dilakukan dengan menggunakan direct message.

Suku cadang dan oli original sebagai produk penunjang disediakan dengan maksud untuk efisiensi waktu dan tenaga. Mengapa original? Agar tidak terjadi kendala dalam pemasangan selain sifatnya durable. Konsep one-stop shop tersebut dikelola dalam menajemen yang sama. Berdasarkan observasi langsung dan wawancara, pada umumnya usaha bengkel kecil pemula mengabaikan konsep tersebut dan hanya fokus pada perbaikan sepeda motor yang sifatnya berat. Perbaikan tersebut 
Website : http://sosial.unmermadiun.ac.id/index.php/sosial

seringkali dilakukan selama berhari-hari, salah satu penyebabnya adalah banyaknya waktu yang digunakan untuk pencarian suku cadang dan seringkali ditambah lamanya pekerjaan pemasangan jika suku cadang yang diinginkan konsumen adalah nonoriginal dengan pertimbangan harga. Selain tersebut, standardisasi jasa harus dilakukan secara konsisten oleh mekanik maupun pengelola bengkel dengan cara mengikuti pelatihan/ training.

\section{Harga (Price)}

Menurut Kotler dan Amstrong, harga merupakan factor utama penentuan posisi dan harus diputuskan sesuai dengan pasar sasaran, bauran ragam produk, dan pelayanan, serta persaingan (Widjaja, 2009). Penetapan harga akan mempengaruhi pendapatan total dan biaya. Harga pada jasa bengkel Suzuki Magetan tergolong tinggi dibandingkan harga pada bengkel takresmi. Strategi premium merupakan perbandingan kesesuaian antara nilai ekstrem, yaitu harag tinggi dengan kualitas tinggi. Strategi tersebut pun mempertimbangkan persaingan, target market, kombinasi product service dan cost based. Harga tinggi memberi persepsi kualitas tinggi sehingga dapat mempengaruhi kurva permintaan yang positif.

Potongan harga jasa berlaku jika pembelian (jasa) diikuti pembelian retail penunjang seperti oli dan suku cadang yang sedang dalam masa promo. Waktu pembayaran, sebagaimana dalam Pedoman Standard Pelayanan Berkualitas Dan Manual Standarisasi Bengkel Suzuki Motor, dilakukan setelah selesai semua pekerjaan yang tertulis dalam SPK (surat perintah kerja), dimana sebelumnya service counter telah harus menjelaskan total biaya yang harus dibayar lalu konsumen menandatangani bukti pembayaran dan penerimaan kunci kendaraan.

Pengkomunikasian harga melalui media sosial seperti facebook, whatsaap, short message, dan word-of-mouth. Sumber komunikasi adalah service counter dan mekanik sebagai teamwork. Dalam usaha jasa bengkel kecil-pemula, kegiatan tersebut dapat dilakukan pemilik sendiri karena pada umumnya usaha tersebut belum memiliki pekerja. Pengkomunikasian dengan menggunakan media tersebut sangat mudah dan murah. Hampir tidak ada masyarakat yang tidak menggunakan media sosial dan whatsapp. Media tersebut digunakan untuk menunjang pekerjaan karena harga murah daripada menggunakan media lain.

\section{E. Lokasi(Place) / Cyberspace \& Time.}

Lokasi yang strategis, bangunan, kelengkapan seperti dekorasi, menjadi faktor penting perusahaan. Lokasi strategis akan memperkecil energi dan waktu serta memberi kemudahan kepada konsumen. Dekorasi yang tepat dapat mempengaruhi emosi konsumen.

Kondisi bangunan merupakan salah satu persyaratan yang memberikan kenyamanan. Berdasarkan observasi langsung, pada umumnya kondisi bangunan usaha bengkel kecil-pemula cenderung seadanya. Dari hasil wawancara dengan konsumen bengkel Suzuki Magetan, kondisi tersebut membuat tidak nyaman saat menunggu, terutama untuk wanita karir dan anak-anak.

Cyberspace merupakan lingkungan media baru juga digunakan oleh bengkel Suzuki Magetan yaitu WWW.suzuki.co.id. Jaman sekarang perkembangan komunikasi sangat pesat terutama komunikasi dengan perantara media massa (Hariyani, 2018). Dalam cyberspace tersebut terdapat alamat yang bisa di klik pada lokasi atau direction, jam kerja, komunikasi dengan masyarakat melalui review, dll. Selain itu, memaksimalkan komunikasi dengan masyarakat dan pelanggan dalam social media. Walaupun komunikasi menggunakan tulisan dan symbol, tetapi komunikasi pada umumnya berlanjut secara nyata di dalam bengkel. Hubungan antar-individu di dunia siber bukanlah sekedar hubungan yang dikatakan sebagai "substanceless hallucination" semata; pada dasarnya hubungan itu terjadi secara nyata, memiliki arti, dan juga bisa berdampak/berlanjut pada kehidupan yang sesungguhnya (Nasrullah, 2014). Lebih lanjut, Howard Rheingold (1993) menyatakan bahwa cyberspace merupakan ruang konseptual dimana semua kata, hubungan manusia, data, kesejahteraan dan juga kekuatan dimanifestasikan oleh setiap orang melalui teknologi CMC (Computer Mediated Communication). Usaha bengkel kecil-pemula hampir keseluruhan memiliki account media sosial baik menggunakan nama pribadi pemilik maupun nama bengkel, tetapi jarang membuat bengkel di dunia siber yang bisa dibuat misalnya melalui google map agar mudah diketahui oleh masyarakat dan sebagai sarana berkomunikasi dengan masyarakat. Pembuatannya cukup mudah dan tidak memerlukan biaya.

\section{F. Promosi (Promotion)}

Tahap penyusunan strategi promosi bengkel Suzuki Magetan adalah:

1). Menentukan communication objectives, yaitu need recognition, finding buyers, brand building, decision to purchase, customer retention, dan product positioning.

2). Promotion mix dan strategi yang digunakan yaitu personal selling antara service counter dan juga mekanik dengan orang yang dijumpai baik di dalam maupun di luar bengkel; sales promotion berupa price reduction pada jasa jika diikuti pembelian suku cadang atau oli, price reduction dan incentive pembelian suku cadang bagi pemilik bengkel kecil-pemula, garansi satu minggu untuk jasa perawatan dan perbaikan, free service untuk perawatan 1x jika telah melakukan perawatan kendaraan selama 5x, gratis pada saat service campaign biasanya dilakukan saat event, gratis perawatan kendaraan tiap hari jum'at pada bulan yang ditentukan dengan ketentuan daftar terlebih dahulu melalui whatsaap, telepon, SMS; direct marketing dengan menggunakan SMS dansocial media.

3). Menentukan bujet promosi. Bujet promosi bergantung pada media yang digunakan dan waktu. Media sosial menghemat bujet promosi hingga $80 \%$ (delapan puluh persen). 
Website : http://sosial.unmermadiun.ac.id/index.php/sosial

\section{G. People}

Pengetahuan yang dimiliki karyawan merupakan hal penting untuk kelangsungan suatu perusahaan. Pengetahuan adalah information based intangibles yang dapat terakumulasi menjadi stock accumulated information dalam perusahaan (Kasali, 2010). Pengetahuan dibidang teknik mesin diperluas melalui training mekanik khususnya untuk teknologi baru. Selain itu, mekanik diwajibkan belajar sendiri melalui tutorial yang ada di berbagai website.

Bagi sebagian bengkel kecil-pemula training mungkin memberatkan, baik dari segi biaya maupun kesulitan kemana mereka mengikuti training, karena training yang dijelaskan diatas diorganisir untuk mekanik bengkel resmi. Suzuki Magetan dan beberapa bengkel resmi lainnya menerima mitra bengkel non-resmi khususnya untuk usaha bengkel kecil-pemula supaya dapat mengikuti perkembangan ilmu pengetahuan dan teknologi mesin sepeda motor.

Faktor lainnya dalam people adalah attitude dan motivasi dari karyawan. Attitude mekanik tercermin dari penampilan, ekspresi wajah, body language, tutur kata. Penampilan berupa rambut, pakaian, sepatu harus bersih dan rapi. Pada saat mencoba kendaraan harus sopan, misalnya pada saat mencoba gas tidak diperbolehkan berlebihan karena bisa menimbulkan polusi suara. Attitude harus selalu dijaga baik pada di dalam kantor maupun di luar kantor. Berdasarkan observasi dan wawancara, pada umumnya penampilan people bengkel kecil-pemula kurang diperhatikan, bahkan terkesan kotor, berbau oli/bensin, dan tidak rapi. Konsumen tidak nyaman dengan penampilan seperti itu. Motivasi karyawan diperlukan agar dapat mewujudkan pesan moment of truth dan jasa yang ditawarkan pada level yang diekspektasikan (Widjaja, 2009). Loyal, skilled and motivated employees who can work well independently or together in teams represent a key competitive advantage(Lovelock, Patterson, Wirtz, 2015).

People merupakan asset utama dalam perusahaan jasa, sebagai contoh, sebelum tahun 2015 banyak konsumen yang memutuskan untuk tidak lagi menggunakan jasa bengkel Suzuki Magetan karena mengikuti mekanik yang pindah tempat bekerja atau mendirikan usaha bengkel sendiri. Konsumen pada perusahaan jasa cenderung fanatik pada karyawan berkinerja tinggi. Strategi meliputi keputusan menyangkut misi perusahaan, penentuan tujuan dan sasaran perusahaan, serta pengembangan strategi yang efektif dan efisien (hariyani, 2013). Many services will always need direct interaction between customers and service employees(Lovelock, Patterson, Wirtz, 2015).

\section{H. Process of Service Production}

Mutu layanan jasa bergantung pada proses penyampaian jasa kepada konsumen, provider jasa adalah karyawan sendiri maka untuk menjamin mutu layanan seluruh perusahaan harus dijalankan sesuai sistem dan prosedur yang terstandardisasi oleh kompetensi, komitmen, dan loyal pada perusahaan (Widjaja, 2009). Process of service production bengkel Suzuki Magetan adalah berdasarkan Pedoman Standard Pelayanan Berkualitas dan Manual Standarisasi Bengkel Suzuki Motor agar tidak mengakibatkan konsumen frustasi dan menghindari agar tidak terjadi salah paham antara konsumen dan teamwork bengkel Suzuki Magetan. Poorly designed processing systems make it very difficult for frontline staff to do their jobs well (Lovelock, Patterson, Wirtz, 2015). Tetapi berdasarkan observasi, peran service marketing representative (SMR) dan service advisor (SA) dilaksanakan oleh service counter, dan peran kepala mekanik dilakukan oleh masing-masing mekanik. Pedoman tersebut disosialisasikan pada karyawan baru dalam teamwork bengkel serta diberikan pada saat briefing sebagai pengingat, berisi delapan langkah standar pelayanan berkualitas antara lain:

1). Booking service berisi definisi, tujuan, pelaksana, prosedur, dokumen, form dan material, flowchart, dan metode kerja.

2). Pendaftaran servis berisi definisi, tahapan, ruang lingkup, pelaksana, prosedur, dokumen, form dan material, flowchart, dan metode kerja.

3). Proses pengerjaan berisi tujuan, ruang lingkup, tahapan, pelasana, prosedur, dokumen, form dan material, flowchart, dan metode kerja

4). Tindak lanjut proses pengerjaan berisi tujuan, prosedur, pelaksana, dokumen, form dan material, flowchart, dan metode kerja

5). Pra-penyerahan berisi tujuan, tahapan, ruang lingkup, pelaksana, prosedur, dokumen, form dan material, flowchart, dan metode kerja.

6). Penyerahan berisi tujuan, ruang lingkup, pelaksana, prosedur, dokumen, form dan material, flowchart, dan metode kerja.

7). Tindak lanjut pasca servis berisi tujuan, ruang lingkup, pelaksana, prosedur, dokumen, form, material, flowchart dan metode kerja.

8). Tindak lanjut retensi tujuan, ruang lingkup, pelaksana, prosedur, dokumen, form, material, flowchart dan metode kerja.

\section{Physical Evidence (tangible cues)}

Bangunan bengkel menjadi nilai tambah bagi konsumen. Seringkali konsumen melihat bangunan sebagai pandangan pertama. Interior bengkel Suzuki Magetan sederhana tetapi tata ruang tunggu serta area bengkel lapang, bersih, dan tidak beraroma material bengkel, sehingga konsumen mood dan merasa nyaman seperti dalam rumah sendiri. Pada umumn ya usaha bengkel tidak memperhatikan kebersihan dan ruang tunggu konsumen seadanya, hal itu membuat konsumen terutama perempuan kurang menyukai kondisi tersebut. Physical surroundings and other visible cues can have a profound effect on the impressions customers form about the quality of the service they receive (Lovelock, Patterson, Wirtz, 2015).

Product mix disertai konsep one-stop-shop, penerapan strategi harga premium, serta dijalankan oleh teamwork yang memiliki pengetahuan serta attitude dan motivasi, promosi yang disusun secara sistematis, process of service production berdasarkan Pedoman Standard Pelayanan Berkualitas dan Manual Standarisasi Bengkel Suzuki Motor, serta physical evidencel 
Website : http://sosial.unmermadiun.ac.id/index.php/sosial

tangible cues sederhana dan memberi kenyamanan konsumen, merupakan service marketing mix yang di rencanakan dan diimplementasikan oleh small business usaha bengkel sepeda motor Suzuki Magetan selama satu semester (enam bulan) serta dievaluasi di akhir semester. Jika pada evaluasi program-program yang diimplementasikan berhasil maka program akan lebih ditingkatkan dan dimodifikasi agar konsumen tidak jenuh. Tetapi apabila tidak tercapai, maka diadakan perbaikan pada program tersebut untuk dijalankan pada semester selanjutnya.

\section{IV.KESIMPULAN DAN SARAN}

Product mix disertai konsep one-stop-shop, penerapan strategi harga premium, serta dijalankan oleh teamwork yang memiliki pengetahuan serta attitude dan motivasi, promosi yang disusun secara sistematis, process of service production berdasarkan Pedoman Standard Pelayanan Berkualitas dan Manual Standarisasi Bengkel Suzuki Motor, serta physical evidencel tangible cues sederhana dan memberi kenyamanan konsumen, merupakan service marketing mix yang di rencanakan dan diimplementasikan oleh small business usaha bengkel sepeda motor Suzuki Magetan selama satu semester (enam bulan) serta dievaluasi di akhir semester. Jika pada evaluasi program-program yang diimplementasikan berhasil maka program akan lebih ditingkatkan dan dimodifikasi agar konsumen tidak jenuh. Tetapi apabila tidak tercapai, maka diadakan perbaikan pada program tersebut untuk dijalankan pada semester selanjutnya.

\section{UCAPAN TERIMA KASIH}

Penelitian ini dipersembahkan untuk LPPM Universitas Merdeka Madiun yang telah memberikan anggaran hingga selesainya penelitian.

\section{VI.DAFTAR PUSTAKA}

Allen, M., Titsworth. S. \& Hunt.S.K. (2009). Quantitave Research in Communication. United State of America: Sage Publication, Inc. Czinkota, M.R., Ronkainen, M.H. Moffet., \& E.O. Moynihan. (2001). Global Business. Philadelphia: Harcourt College Publishers. Dharmmesta.Basu S \& Hani Handoko. (2016). Manajemen pemasaran. analisis perilaku konsumen. Edisi pertama. Yogyakarta: BPFE-Yogyakarta. Hariyani, N. (2013). Ekonomi Media Surat Kabar Lokal. Jurnal Ilmu Komunikasi, 1-82.

Hariyani, N. (2018). Analisa Semiotika Representasi Citra Perempuan Dalam Film Kartini. SOSIAL, 19-42.

Kasali, R. (2010). Myelin. Mobilisasi Intangibles Menjadi Kekuatan Perubahan. Jakarta: Kompas Gramedia .

Lovelock, Patterson, Wirtz. (2015). Services Marketing. An Asia Pacific and Australian Perpective. 6th edition. Melbourne: Pearson Australia.

Moriarty, Sandra. Mithcell.Nancy. Wells, William. (2011). Advertising. Jakarta: Kencana Prenada Media Group.

Murti,Endang, Retno I, Agus W. (2017). Pemberdayaan Masyarakat Desa Dalam Pengelolaan Alokasi Dana Desa (ADD) di Desa Baderan Kecamatan Geneng Kabupaten Ngawi. Sosial, 160-173.

Nasrullah, R. (2014). Teori dan riset. media siber (cybermedia). Jakarta: Prenada Media Group.

Sejati, V. A. (2015). Strategi Periklanan Pada Bisnis Retail. ASPIKOM, 235-242. Retrieved from JURNAL ASPIKOM: JURNALASPIKOM.ORG

Sejati, V. A. (2017). Handling of Costumer Complaint on the Small Business Services Field. Global Scientific Journals, 119-125.

Sejati, V. A. (2017). Peranan Sales Force Terhadap Repurchase Suzuki R2 Area Magetan. Sosial, 185-192.

Sejati, V. A. (2018). Marketing Communication,Direct Marketing,Public Relation and Advertising. Germany: Grin Verlag.

Sugiyono. (2013). Metode Penelitian Kuantitatif Kualitatif dan RD. bandung : Alfabeta.

Sujarweni, V. (2014). Metodologi Penelitian. Yogyakarta: pustakabarupress.

Tjiptono. Fandy; \& G. Chandra. (2005). Service, Quality and Satisfaction. Yogyakarta: Andi offset.

Widjaja, B. T. (2009). Lifestyle Marketing. PT.Gramedia: Jakarta 